\title{
Physcomitrella patens Activates Defense Responses against the Pathogen Colletotrichum gloeosporioides
}

\section{Guillermo Reboledo ${ }^{1}$, Raquel del Campo ${ }^{1}$, Alfonso Alvarez ${ }^{1,2}$, Marcos Montesano ${ }^{2}$, Héctor Mara ${ }^{1}$ and Inés Ponce de León ${ }^{1, *}$}

1 Department of Molecular Biology, Clemente Estable Biological Research Institute, Avenida Italia 3318, CP 11600 Montevideo, Uruguay; E-Mails: greboledo@iibce.edu.uy (G.R.); rdelcampo@iibce.edu.uy (R.C.); aalvarez@cin.edu.uy (A.A.); hmara40@hotmail.com (H.M.)

2 Laboratory of Plant Physiology, Nuclear Research Center, Faculty of Sciences, Mataojo 2055, CP 11400 Montevideo, Uruguay; E-Mail: montesano@cin.edu.uy

* Author to whom correspondence should be addressed; E-Mail: iponce@iibce.edu.uy; Tel.: +2-598-2487-2605; Fax: +2-598-2487-5548.

Academic Editor: Jan Schirawski

Received: 16 July 2015 / Accepted: 28 August 2015 / Published: 15 September 2015

\begin{abstract}
The moss Physcomitrella patens is a suitable model plant to analyze the activation of defense mechanisms after pathogen assault. In this study, we show that Colletotrichum gloeosporioides isolated from symptomatic citrus fruit infects $P$. patens and cause disease symptoms evidenced by browning and maceration of tissues. After C. gloeosporioides infection, $P$. patens reinforces the cell wall by the incorporation of phenolic compounds and induces the expression of a Dirigent-protein-like encoding gene that could lead to the formation of lignin-like polymers. C. gloeosporioides-inoculated protonemal cells show cytoplasmic collapse, browning of chloroplasts and modifications of the cell wall. Chloroplasts relocate in cells of infected tissues toward the initially infected $C$. gloeosporioides cells. $P$. patens also induces the expression of the defense genes $P A L$ and $C H S$ after fungal colonization. $P$. patens reporter lines harboring the auxin-inducible promoter from soybean (GmGH3) fused to $\beta$-glucuronidase revealed an auxin response in protonemal tissues, cauloids and leaves of $C$. gloeosporioides-infected moss tissues, indicating the activation of auxin signaling. Thus, P. patens is an interesting plant to gain insight into defense mechanisms that have evolved in primitive land plants to cope with microbial pathogens.
\end{abstract}


Keywords: Physcomitrella patens; Colletotrichum gloeosporioides; defense responses; cell wall; chloroplasts relocation; gene expression; auxin signaling

\section{Introduction}

Plants respond to pathogen attack by activating the production of a variety of defense-related compounds. After pathogen perception, signaling cascades are activated leading to the increase of reactive oxygen species (ROS), synthesis of antimicrobial compounds, fortification of the cell wall and induction of defense-related genes [1]. The induction of many of these responses is common to both resistant and susceptible hosts, and the outcome of the interaction relies on an effective and rapid host defense response. The hypersensitive response (HR) is a form of cell death that occurs in infected tissues to restrict pathogen growth [2]. Studies in flowering plants have shown that some necrotrophic pathogens need HR cell death to achieve full pathogenicity $[3,4]$. The biosynthesis of hormones such as salicylic acid, ethylene, jasmonic acid, auxin and abscisic acid is also induced after pathogen recognition and play key roles in plant defense responses [5,6]. Depending on the pathogen, different hormonal pathways are activated leading to resistance to particular pathogens [5]. In addition, some pathogens can produce themselves phytohormones interfering with the plant defense [7].

Colletotrichum species are a group of ascomycete plant pathogens that infect and cause anthracnose disease in a wide range of plant species including important crops [8]. Many Colletotrichum species are hemibiotrophs having initially a biotrophic phase of infection in living host plant cells and a second destructive necrotrophic mode of infection [9,10]. Colletotrichum gloeosporioides (C. gloeosporioides) has been associated with at least 470 different host species and is considered as the major causal agent of post-harvest disease in fruits such as citrus, apple, olive, mango, banana and strawberries [11]. On citrus, postharvest anthracnose of fruit is caused by C. gloeosporioides (Penz.) Penz. and Sacc. in Penz [12]. C. gloeosporioides is a primary invader of injured or weakened tissues leading to un-marketable infected citrus fruits [12]. Infected tissues are usually symptomless and the disease becomes visible, when the peel of the fruit is injured or the fruit is exposed to stress conditions or become senescent $[12,13]$. Conidia of $C$. gloeosporioides germinate on the surface of the fruit forming melanized appresoria which remains as quiescent infections [13]. When tissues die or are weakened by stress, they are rapidly colonized by $C$. gloeosporioides and acervuli are formed, completing the life cycle [12]. Symptoms of postharvest anthracnose in citrus fruit can vary and lesions can occur around a senescent button before spreading to adjacent rind or form brown to black spots that become sunken on the rind tissues [14]. Post-harvest anthracnose in citrus is increased by ethylene degreening, which is a method used to improve fruit color $[12,13,15]$.

Mosses are bryophytes that are infected with several fungal pathogens which are capable of producing disease in different crops [16]. In mosses, the fungi Botrytis cinerea, Alternaria alternata, Fusarium avenaceum and Fusarium oxysporum, and the oomycetes Pythium irregular and Pythium debaryanum, cause severe necrosis in tissues leading to plant maceration and death [16-19]. Other fungal pathogens such as Cladosporium oxysporum and Epicoccum nigrum cause milder discoloration or chlorosis in mosses $[16,20]$. In response to $B$. cinerea, $P$. irregulare and $P$. debaryanum infection, $P$. patens activate 
a defense response, evidenced by the fortification of the plant cell wall and induction of defense related genes encoding phenylammonia lyases (PAL) and chalcone synthase (CHS) $[18,19]$. Other defense mechanisms are activated in $P$. patens in response to $B$. cinerea and elicitors of the phytopathogenic bacteria Pectobacterium carotovorum sp. carotovorum (P.c. carotovorum), including the activation of an HR-like response, the induction of genes encoding oxylipin producing lipoxygenases, and the accumulation of oxylipins derived from an alpha-dioxygenase [17-19,21]. In addition, it was recently shown that the auxin signaling pathway is activated in $P$. patens after $P$. irregulare and $P$. debaryanum infection [22]. In the present work we analyzed if an isolate of $C$. gloeosporioides obtained from symptomatic citrus fruits was capable of infecting $P$. patens tissues and activating a defense response. Since we have observed that most necrotophic pathogens cause cell wall fortification and induce the expression of defense genes encoding PAL and CHS, we analyzed these responses, and included the available GH3::GUS reporter line to analyze auxin signaling in response to this pathogen. We show that $C$. gloeosporioides infects $P$. patens cells and cause disease symptoms evidenced by browning of moss tissues and maceration. In response to pathogen infection $P$. patens reinforces the cell wall, changes chloroplast distribution in the infected and the neighbor cells, induces the expression of defense related genes and activates auxin signaling.

\section{Results and Discussion}

\subsection{Colletotrichum gloeosporioides Isolated from Orange Fruits Infects P. patens and Causes}

Disease Symptoms

A strain of Colletotrichum spp., which was genotypically identified as C. gloeosporioides, was obtained from a citrus fruit naturally infected, and with dark dry brown lesions that become sunken on the rind tissues (Figure 1A). Small pieces of the citrus lesions were inoculated on the medium leading to the formation of colonies with abundant grey mycelium (Figure 1B,C). The asexual spore-bearing structure known as acervuli produced orange to pink masses of conidia (Figure 1D,E). A monosporic culture was obtained (Figure $1 \mathrm{~F}$ ) and a monosporic conidial suspension was artificially inoculated in citrus fruit developing a brown lesion with sunken parts after 7 days of inoculation (Figure 1G). The isolate recovered from the artificially symptomatic tissue were morphologically identical to the original isolate obtained from the naturally infected fruit, fulfilling Koch's postulates (Figure 1H,E). The C. gloeosporioides strain produced typically cylindrical aseptate conidia with rounded ends (Figure 1H) [23], showing at one of the ends an abscission scar (Figure 1I). In order to analyze if C. gloeosporioides infects $P$. patens, moss colonies were inoculated with a conidial suspension and microscopic analysis were conducted. Four hours after inoculation (HAI), several conidia germinated, developed a septa, and formed a germ tube on the surface of moss leaves (Figure 1J). This suggests that like in flowering plants, conidia germination and formation of infection structures in $P$. patens, require contact with a hard surface and probably host signals [24]. C. gloeosporioides fungal proteins involved in cytokinesis, polarized cell division and differentiation of the germ tube to appresorium formation have been identified $[25,26]$. 

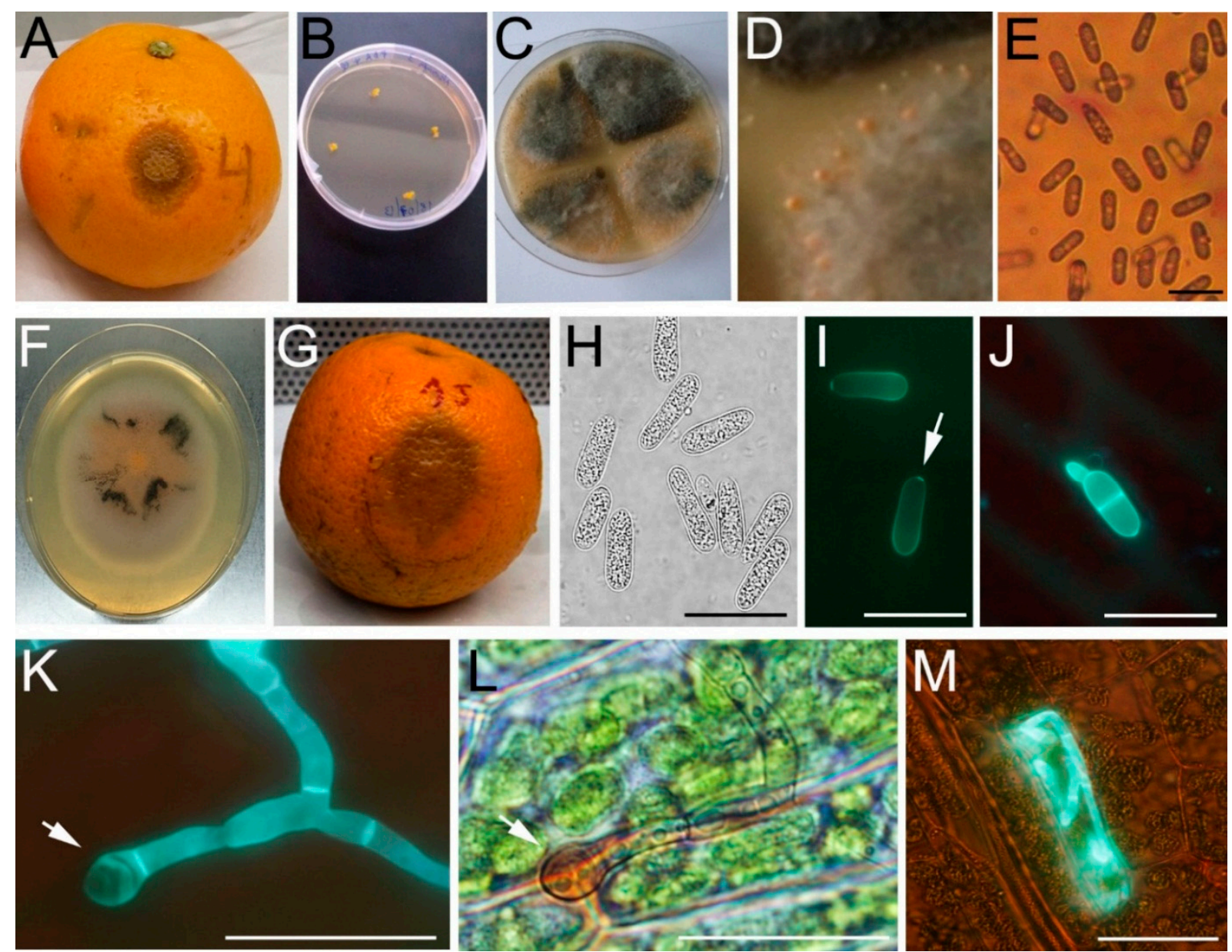

Figure 1. Isolation of $C$. gloeosporioides strain and infection of $P$. patens tissues. (A) Symptomatic citrus fruit; (B) Small pieces of symptomatic citrus lesion inoculated on Potato Dextrose Agar (PDA); (C) Mycelium grown from infected citrus lesion; (D) A closer view of $\mathrm{C}$ showing the acervuli; (E) Conidial suspension obtained from the orange mucilage; (F) Colony from monosporic conidial suspension; (G) Artificially inoculated citrus fruit; $(\mathbf{H}, \mathbf{I})$ C. gloeosporioides conidia morphology. Abscission scar of conidia is indicated with a white arrow in $\mathbf{I} ;(\mathbf{J})$ Germinated conidia on leaf surface showing germ tube and septa; $(\mathbf{K})$ C. gloeosporioides hyphae growing on leaf surface stained with solophenyl; (L) Same picture as $\mathbf{K}$ showing brown mature appresorium. Appresorium is indicated with a white arrow in $\mathbf{K}$ and $\mathbf{L}$; (M) Intracellular growth of hyphae in moss leaf cell. Scale bars represent $20 \mu \mathrm{m}$ in $\mathbf{E}, \mathbf{H}-\mathbf{L}$ and $50 \mu \mathrm{m}$ in $\mathbf{M}$.

At 24 HAI germ tubes ramified and melanized appresoria were distinguished on the leaves surfaces (Figure $1 \mathrm{~K}-\mathrm{L}$ ), and at $48 \mathrm{HAI}$ several moss cells were infected evidenced by fungal hyphae growing inside the cells (Figure 1M). Melanin impregnation of the appressoria wall enables Colletotrichum species to build up a high osmotic pressure and penetrate the cell wall [27]. Under our experimental conditions, we did not observe intracellular vesicles associated to the transient biotrophic phase that precedes tissue colonization in a necrotrophic phase of infection [27]. However, in several interactions of Colletotrichum species with different hosts, the biotrophic stage is absent [28]. Like in flowering plants, adhesion of $C$. gloeosporioides conidia and appressoria occurred preferentially in the juxtapositions of the cells (Figure 1I-K), which may be favorable for the development of the pathogen, and suggest a direct 
process of fungal penetration [29,30]. Direct infection is common among various Colletotrichum species [31], and involves a combination of mechanical force and the degradation of the cell wall by enzymes [32,33]. Stomata and stomatal subsidiary cells are also penetration sites for C. gloeosporioides in some hosts [29,34]. In moss tissues, direct penetration and colonization of wounded tissues is probably the form of invasion by this fungal pathogen since $P$. patens does not have stomata. To the best of our knowledge, this is the first time that a Colletotrichum species is reported to infect a moss.

$P$. patens has distinct developmental stages, including the protonema, which is a filamentous network of cells, and the radially symmetric gametophore, which is a leafy shoot composed of a nonvascular cauloid (stem-like structure) with leaves and rhizoids [35]. Disease development can be easily visualized microscopically since leaves, rhizoids and protonemal filaments are formed of a monolayer of cells. We evaluated symptom development at 1, 2, and 5 days after inoculation (DAI) with C. gloeosporioides. While no clear symptoms were observed in P. patens colonies at 1 DAI (data not shown), moss tissues were susceptible to $C$. gloeosporioides infection at 2 DAI, evidenced by the appearance of brown protonemal tissues at the border of the colonies, brown cells and some brown midline veins in leaves (Figure 2B,E,H), while untreated tissues were green (Figure 2A,D.G). After 5 DAI, protonemal tissues were brown and heavily macerated compared to control green tissues (Figure $2 \mathrm{C}, \mathrm{J}, \mathrm{K}$ ).
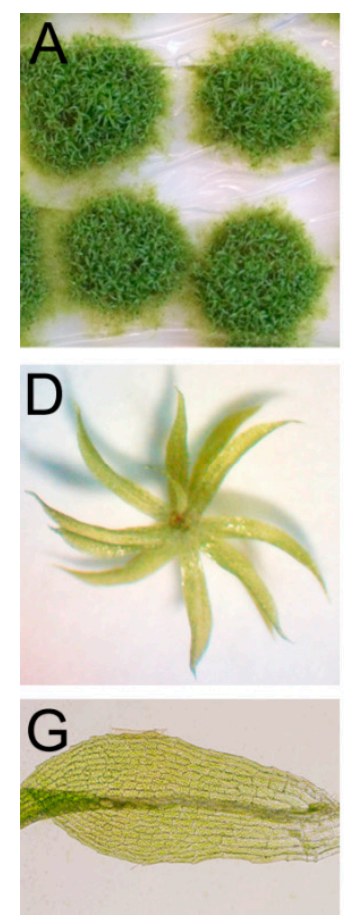
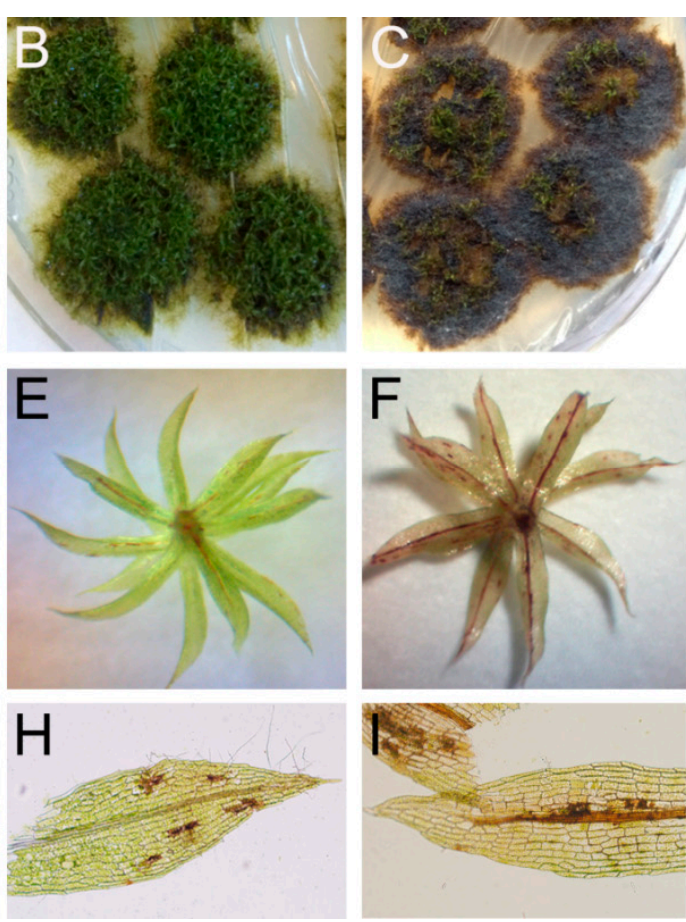
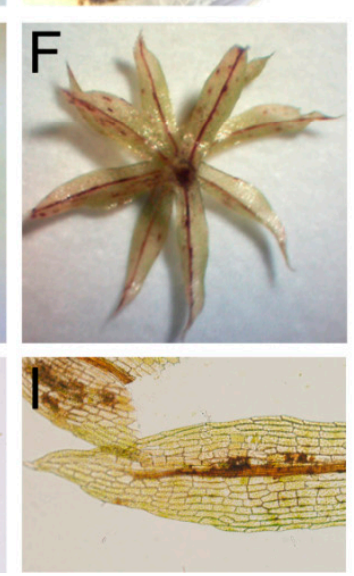
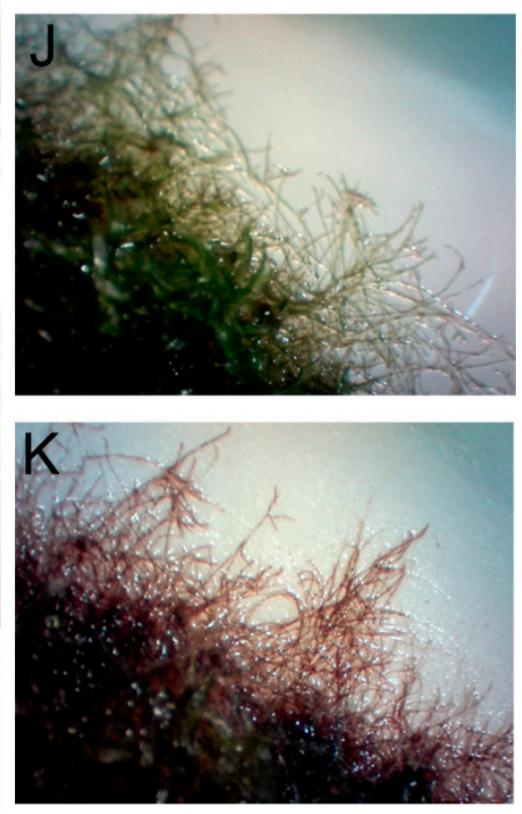

Figure 2. Symptom development in C. gloeosporioides inoculated P. patens tissues. (A) Control moss colonies; (B) C. gloeosporioides infected moss colonies at 2 days after inoculation (DAI); (C) C. gloeosporioides infected moss colonies at 5 DAI; (D) Control gametophore; (E) C. gloeosporioides infected gametophore at $2 \mathrm{DAI} ;(\mathbf{F})$ C. gloeosporioides infected gametophore at $5 \mathrm{DAI}$; $(\mathbf{G})$ control leaf; $(\mathbf{H})$ C. gloeosporioides infected leaf at 2 DAI; (I) C. gloeosporioides infected leaf at 5 DAI; (J) Border of a control moss colony; (K) Border of a moss colony inoculated with C. gloeosporioides at 5 DAI. In D, E and $\mathbf{F}$ gametophores were cut at the lower part of the cauloid and placed upside down for proper visualization of symptoms. 
Five day-inoculated leaves had brown midline veins and brown cells in leaves (Figure 2F-I). Browning and necrosis of tissues is a typical symptom caused by C. gloeosporioides in flowering plants [15,36]. During the necrotrophic phase of infection by Colletotrichum species, the activity of cell wall degrading enzymes such as endopolygalacturonase and pectate lyase increases [28]. Pectate lyases contribute to virulence in $C$. gloeosporioides and mutants in these type of enzymes produce smaller lesions in avocado [37]. Other cell wall degrading enzymes such as cellulase, $\alpha$-mannosidase, and 1,4- $\beta$-xylanase are also virulent factors of $C$. gloeosporioides [38]. Here, we show that $C$. gloeosporioides is able to infect $P$. patens tissues and cause disease symptoms. $P$. patens has only one layer of cells in most of its tissues including leaves, protonemal filaments and rhizoids, which probably facilitates pathogen invasion and tissue maceration.

\subsection{P. patens Activates Cell Wall-Associated Defenses against C. gloeosporioides}

Cell wall modifications are important defense responses against Colletotrichum species since these fungal pathogens often directly penetrate plant cell walls. Consistently, we observed frequently that cell walls of $C$. gloeosporioides-infected cells were brown which could be indicative of phenolic compounds accumulation (Figure 3A,B). We therefore visualized in more detail cell wall-associated defense responses. C. gloeosporioides-infected leaves were stained with safranin-O to measure the incorporation of phenolic compounds. C. gloeosporioides-infected tissues were positively stained (Figure 3D,E), while untreated leaves (Figure 3C) were not stained, reflecting a cell wall reinforcement mechanism. Similarly, in flowering plants deposition of phenolic compounds has been observed after $C$. gloeosporioides infection [29]. These results indicate that the presence of C. gloeosporioides is perceived by $P$. patens, which activates a cell wall fortification mechanism. However, this fortification mechanism is not sufficient to stop fungal colonization leading to plant decay.
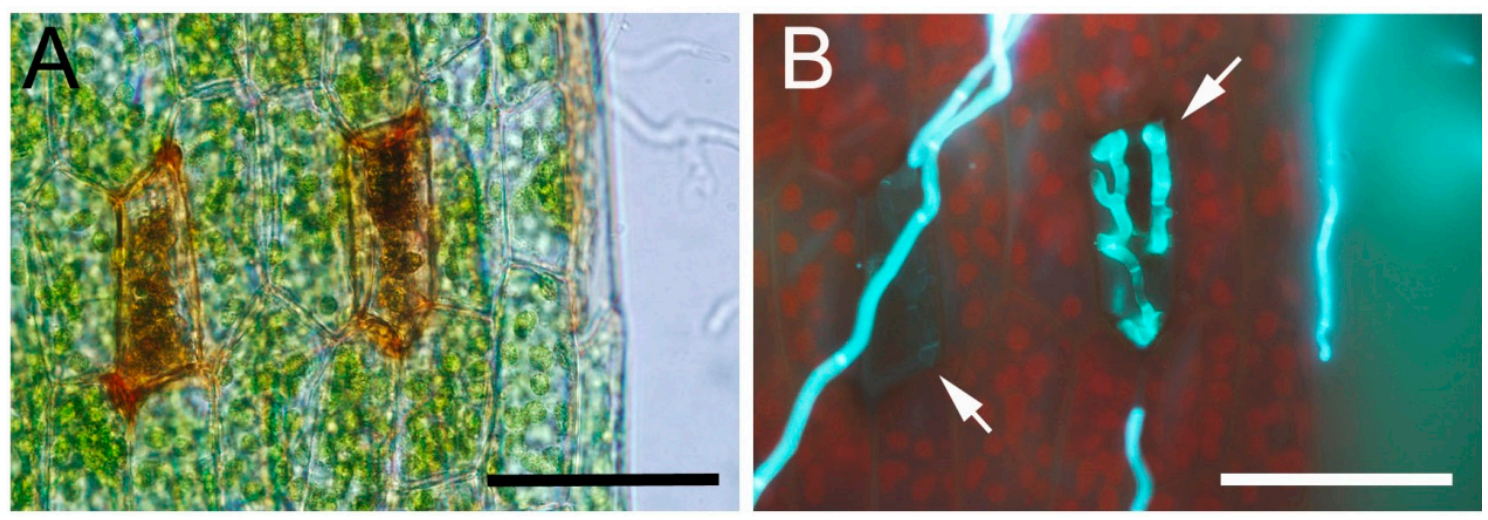

Figure 3. Cont. 

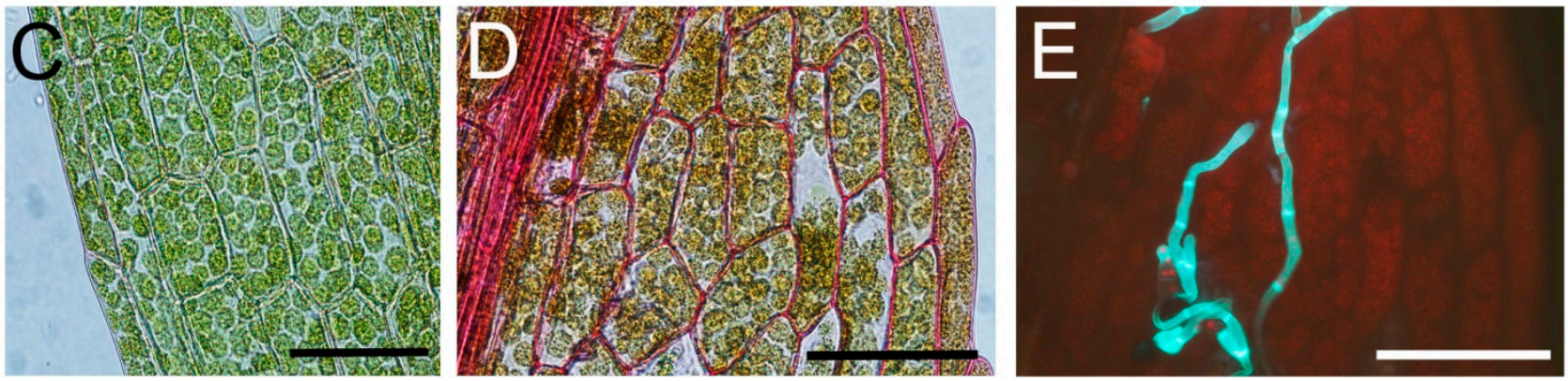

Figure 3. Cell wall-associated defenses in C. gloeosporioides-infected tissues. (A) C. gloeosporioides-infected cells showing brown cell walls at 2 DAI; (B) Same leaf as A stained with solophenyl, hyphae inside the cells are indicated with a white arrow; (C) Control leaf; (D) C. gloeosporioides-infected leaf stained with safranine-O at 2 DAI; (E) Same leaf as D stained with solophenyl. Scale bars represent $50 \mu \mathrm{m}$.

\subsection{Colletotrichum gloeosporioides Infection Causes Cytoplasmic Shrinkage and}

\section{Chloroplasts Repositioning}

Protonemal tissues infected with $C$. gloeosporioides showed cytoplasmic shrinkage, browning of chloroplasts and changes in the cell wall evidenced by staining with the fluorescent dye solophenyl flavine 7GFE 500 (Figure 4A-D). Cytoplasmic shrinkage, browning of the chloroplasts and accumulation of autofluorescent compounds are indicative of an HR-like response. Similar cellular changes occur in $P$. patens tissues infected with HR inducing pathogens such as $B$. cinerea and a $P$. carotovorum strain that have the harpin-encoding gene hrpN [17,19]. An HR is induced in several interactions of C. gloeosporioides with flowering plants, including citrus, cowpea and Arabidopsis [13,29,39]. Although in most of these interactions the HR was associated to a resistant mechanism, some susceptible hosts also displayed an HR response [29]. Necrotrophic pathogens are capable of inducing an HR response for their own benefit [4]. Further studies are needed to understand if the HR-like response in $P$. patens facilitates $C$. gloeosporioides infection.

When $C$. gloeosporioides-inoculated leaves were observed in more detail, a relocation of chloroplasts in cells surrounding a brown-infected cell was evident (Figure 4E). Chloroplasts were redistributed during infection in infected cells and in adjacent non-infected cells chloroplasts relocated close to the cell wall and in proximity to the infected cell (Figure 4E,F).
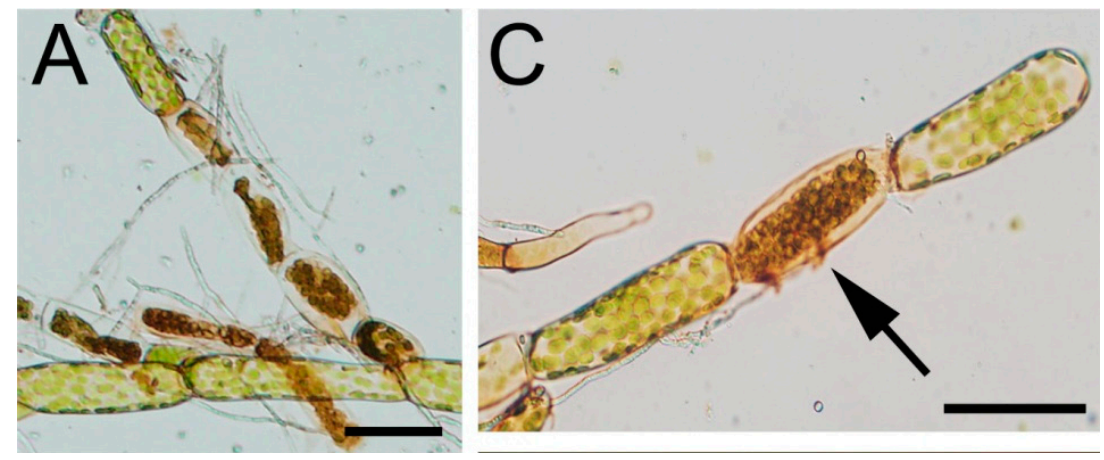

Figure 4. Cont. 

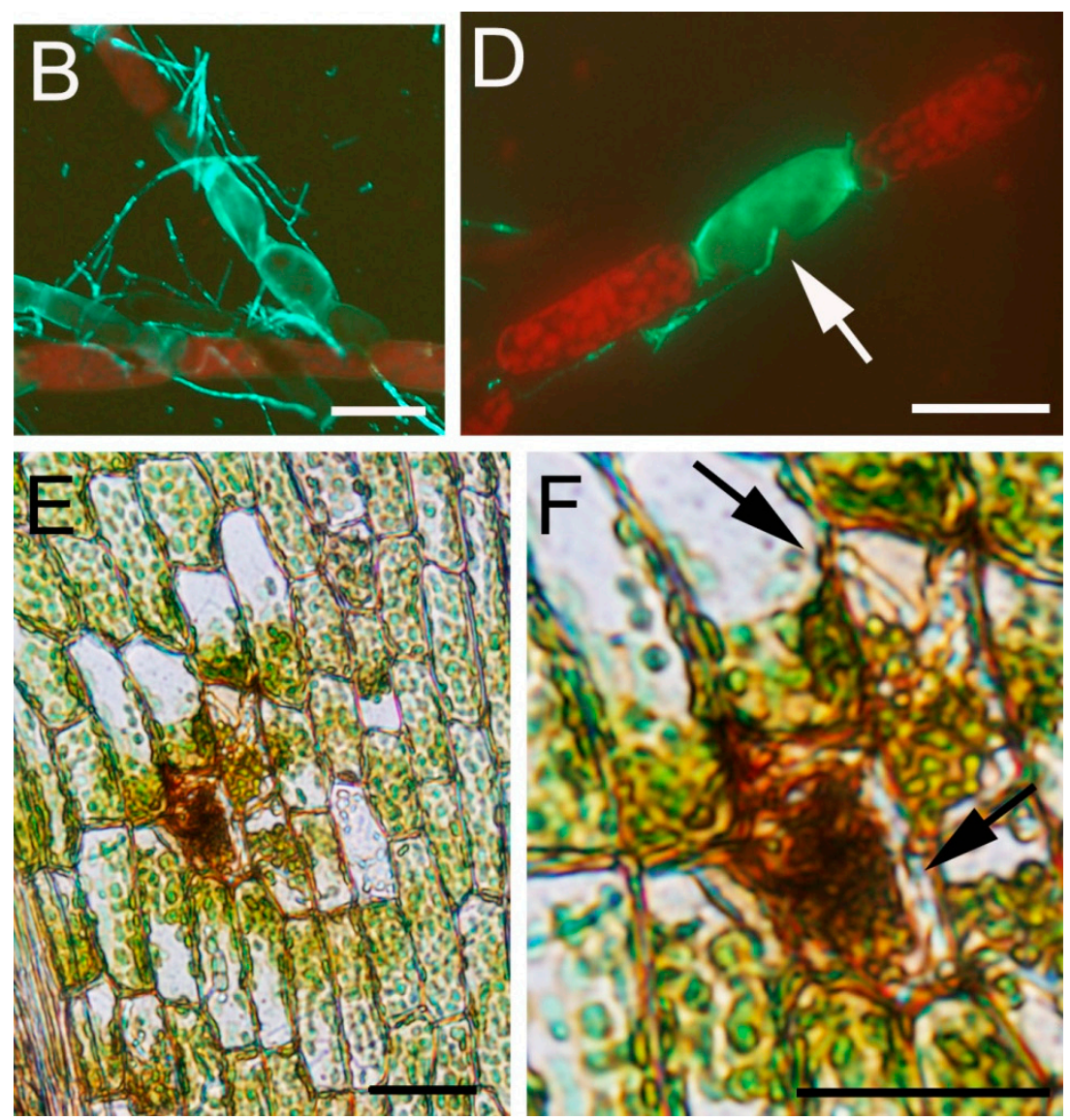

Figure 4. Cytoplasmic shrinkage and intracellular relocation of chloroplasts after C. gloeo-sporioides infection. (A,C) Protonemal tissues inoculated with C. gloeosporioides; (B,D) Protonemal tissues inoculated with C. gloeosporioides and stained with solophenyl; (E) C. gloeosporioides infected leaf showing chloroplast relocation (F) Closer view of $\mathbf{E}$, hyphae are indicated with black arrows. Arrows in $\mathbf{C}$ and $\mathbf{D}$ indicate a hypha in contact with a protonemal cell. Scale bars represent $20 \mu \mathrm{m}$ in $\mathbf{A}-\mathbf{D}$ and $50 \mu \mathrm{m}$ in $\mathbf{E}-\mathbf{F}$.

This type of response has also been observed in $P$. patens tissues infected with other pathogens including $P$. irregulare, $P$. debaryanum, $F$. avenaceum and A. alternata $[18,40]$. However, the precise role of chloroplast repositioning towards the infection site is at present unknown. Chloroplasts play important functions in plant defense against pathogens. These organelles are a rich source of ROS, which act as signaling molecules to induce defense gene expression, are involved in cell wall reinforcement, and have antimicrobial activity [1,41]. Treatment of Arabidopsis with flg22, a peptide derived from bacterial flagellins, induces the formation of calcium transients in chloroplasts, which leads to downregulation of photosynthesis-related genes and upregulation of defense genes [42]. Chloroplasts also host biosynthetic pathways for the production of amino acids, defense hormones and secondary metabolites involved in plant resistance against pathogens [43]. Kwon et al. [44] have demonstrated that in flowering plants, proteins from intact chloroplast are released to the cytoplasm after $P$. carotovorum infection. In addition, during virus infection, the normally chloroplast localized receptor interacting protein (NRIP1) is recruited to the cytoplasm and nucleus before plant defense is activated [45]. Interestingly, Kaplan et al. [46] have demonstrated that in Arabidopsis and Nicotiana, chloroplasts send out dynamic tubular extensions called stromules during innate immunity, which form numerous 
connections with the nucleus. These stromules are involved in the transport of pro-defense signals such as $\mathrm{H}_{2} \mathrm{O}_{2}$ into the nucleus during immunity [46]. In Phytophthora infestans-potato interaction, the nucleus moves to the pathogen contact site [47]. Further studies are needed to understand the role of chloroplasts repositioning during pathogen infection, including the relation with nucleus movement, and the possible effects of proteins or peptides delivered from chloroplasts on plant defense and pathogens growth.

\subsection{P. patens Induces Defense Gene Activation in Response to C. gloeosporioides Infection}

In order to analyze if $P$. patens activates the expression of defense genes in response to C. gloeosporioides, the expression pattern of three defense genes previously known to be induced in this moss in response to pathogen infection was evaluated. The results show that $C$. gloeosporioides infection activates the expression of several defense related genes such as a PAL,CHS and a gene encoding a dirigent-like protein $(D I R)$. All genes were rapidly induced at $4 \mathrm{HAI}$, which correlates with the germination of conidia and the development of the germination tube. The maximum expression levels of the three genes were reached at $24 \mathrm{HAI}$. In case of $P A L$ and $C H S$ two hybridization bands were observed, which correspond to other $P A L$ and $C H S$ genes with high sequence similarity. $P$. patens has higher number of members forming part of the $P A L$ and $C H S$ multigene families compared to flowering plants $[48,49]$, and some of the products produced by these enzymes could play a role in the defense response of this moss to pathogens. P. patens genome contains 13 additional $P A L$ genes, and five of them (Phypa_177179, Phypa_181734, Phypa_178793, Phypa_176961 and Phypa_123073) have higher identity than $80 \%$ to the $P A L$ gene used as a probe (Phypa_156018; $2877 \mathrm{bp}$ ), and encode transcripts varying from 2704 to $3583 \mathrm{bp}$. Northern blot results could represent the expression pattern of several of these PAL-encoding genes. Similarly, P. patens has 16 additional CHS-encoding genes and eight (Phypa_100508, Phypa_101257, Phypa_110814, Phypa_155379, Phypa_98737, Phypa_152430, Phypa_149682 and Phypa_63283) have higher identity than $80 \%$ to the CHS gene used as a probe (Phypa_104998; 2191 bp), and encode transcripts varying from 1924 to $2787 \mathrm{bp}$, which could also represent the expression pattern of some of these CHS-encoding genes observed in the Northern blot analysis. $P A L$ and $C H S$ defense gene expression also increases in flowering plants infected with Colletotrichum species [50,51]. In addition, an increase in PAL activity has been observed in the interaction of $C$. gloeosporioides with cowpea [29], suggesting the involvement of the phenylpropanoid pathway in the defense response against this fungal pathogen. The importance of phenylpropanoid pathway products in the defense response of Medicago truncatula to Colletotrichum trifolii was confirmed in silenced CHS plants which were more susceptible and showed extensive mycelium development compared to control plants [51]. C. gloeosporioides infection also leads to lignification to reinforce the cell wall in flowering plants [29]. DIR proteins mediate the free radical coupling of monolignol plant phenols to yield lignans and lignins [52]. The P. patens DIR-like protein used in this study has $31 \%-40 \%$ identity with DIR proteins of flowering plants. P. patens has eight additional putative DIR-like genes with identities of $39.7 \%-96.7 \%$ to the DIR-like gene (Phypa_110421). As the DIR-like cDNA fragment used as a probe and two other DIR-like genes (Phypa_170601 and Phypa_48771) exhibit higher identity than $80 \%$ and encode transcripts of similar sizes, Northern blot results could represent the expression pattern of these three DIR-like genes. In P. patens DIR expression was also induced in response to B. cinerea inoculation [19]. Thus, DIR-like-proteins could lead to 
the production of lignin-like compounds, with possible roles in defense against pathogens such as C. gloeosporioides.

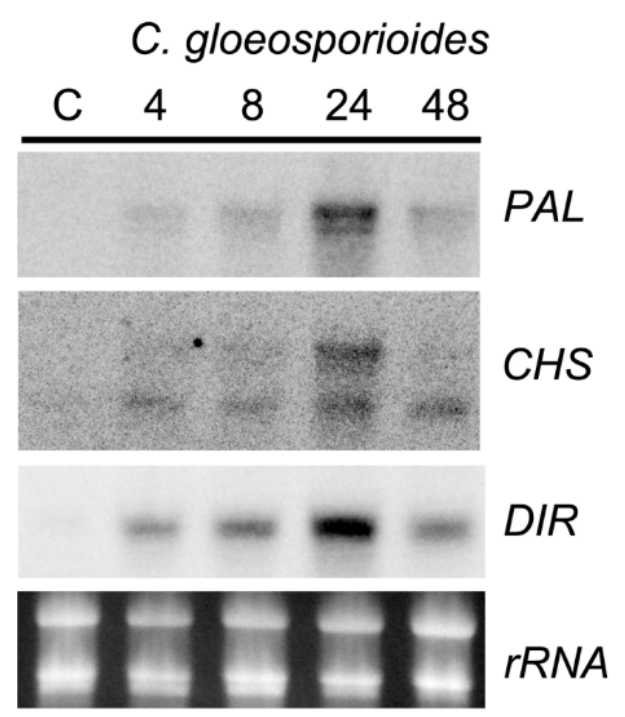

Figure 5. C. gloeosporioides-induced expression of defense genes in P. patens. Expression of phenylammonia lyase $(P A L)$, chalcone synthase $(C H S)$ and dirigent-like $(D I R)$ genes after C. gloeosporioides inoculation. Plants treated during $24 \mathrm{~h}$ with water were used as controls. Moss samples were harvested at the indicated times (hours) after treatment. Ten micrograms of total RNA were separated on formaldehyde-agarose gels, transferred to a nylon membrane and hybridized to the corresponding cDNA probes. Ethidium bromide staining of rRNA was used to ensure equal loading of RNA samples. Experiments were repeated twice with similar results.

\subsection{P. patens Activates Auxin Signaling in Response to C. gloeosporioides Infection}

C. gloeosporioides is able to produce by itself the indole-3-acetic acid (IAA) auxin in culture medium and during infection of flowering plants [53-55]. Therefore, we decided to analyze P. patens reporter lines harboring an auxin inducible promoter from soybean (GmGH3) fused to $\beta$-glucuronidase (GUS) [56], in response to infection with $C$. gloeosporioides. P. patens has two GH3 proteins, which are IAA amino acid conjugate synthetases [57]. The results show that while in control tissues GUS staining was detected in spots around the whole colony, tissues inoculated with C. gloeosporioides at 2 DAI showed an overall GUS staining except at the border of the colonies (Figure 6A,B). Protonemal tissues are composed of caulonemal filaments involved in substrate colonization and nutrient acquisition, and end chloronemal cells that are principally involved in photosynthesis [58]. 

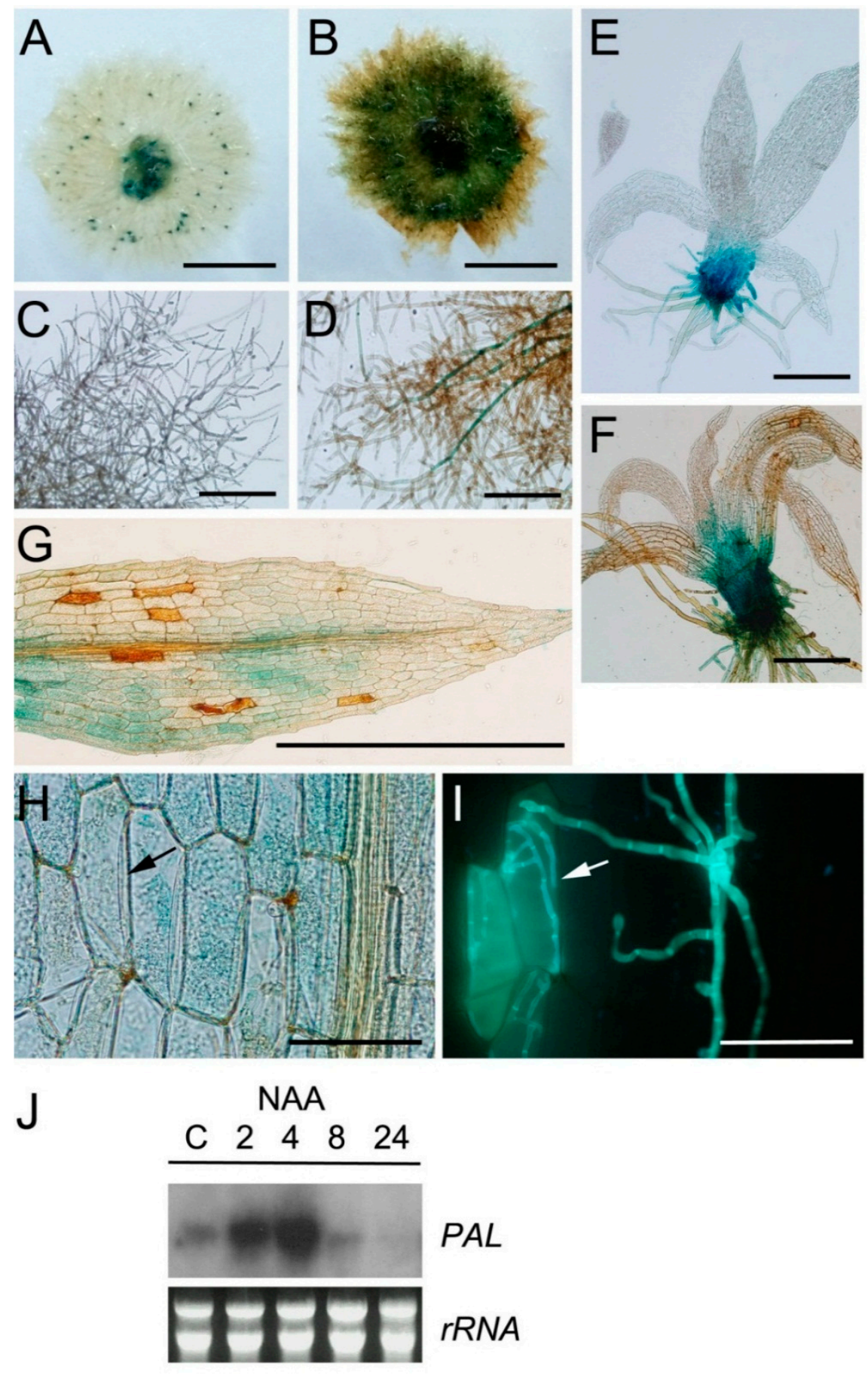

Figure 6. Auxin signaling is activated in P. patens after C. gloeosporioides inoculation. GUS staining of GH3::GUS reporter line in: (A) Untreated colony; (B) C. gloeosporioides-inoculated colony; (C) Untreated protonema; (D) C. gloeosporioides-inoculated protonema; (E) Untreated gametophore; (F) C. gloeosporioides-inoculated gametophore; (G) C. gloeosporioides-infected leaf; (H) C. gloeosporioides-infected leaf; (I) Same leaf as H stained with solophenyl. The black arrow in $\mathbf{H}$ and the white arrow in $\mathbf{I}$ indicate $C$. gloeosporioides-infected cells. All pictures of $C$. gloeosporioides inoculated tissues were taken at $2 \mathrm{DAI}$; (J) Expression of $P A L$ after NAA treatment. Moss samples were harvested at the indicated times (hours) after treatment. Scale bars represent $0.5 \mathrm{~cm}$ in $\mathbf{A}$ and $\mathbf{B} ; 0.5 \mathrm{~mm}$ in $\mathbf{C}-\mathbf{G}$ and $50 \mu \mathrm{m}$ in $\mathbf{H}$ and $\mathbf{I}$. 
Protonemal filaments at the border of the colonies were observed in more detail. Protonemal cells of control colonies did not show GUS accumulation (Figure 6C). In C. gloeosporioides-infected protonemal tissues, GUS expression was detected mainly in caulonemal filaments, while chloronemal cells at the border of the colony were not stained (Figure 6D). In control plants GUS was expressed in the basal part of the gametophore (Figure 6E), which is a location of high auxin occurrence [56], leading to the blue spots appearance observed in Figure 6A. When C. gloeosporioides infected gametophores were analyzed, the whole cauloid was stained and some GUS stained cells were detectable in leaves (Figure 6F,G). Cells surrounding infected C. gloeosporioides cells accumulated GUS (Figure 6H,I). Thus, the results show that auxin signaling is upregulated in $P$. patens tissues infected with $C$. gloeosporioides as evidenced by increased GH3::GUS expression. Since P. patens could increase auxin production to induce gene expression needed in the defense response against $C$. gloeosporioides, we analyzed if auxin induced $P A L$ expression. The results shown that treatment with auxin (NAA) increased rapidly PAL (Phypa_156018) transcript levels in moss tissues (Figure 6J). Interestingly, in citrus flowers, one of the genes most strongly upregulated in response to Colletotrichum acutatum is the GH3-encoding gene [59]. GH3::GUS expression also increases in $P$. patens tissues infected with the oomycetes $P$. irregulare and $P$. debaryanum [22]. In addition, PAL (Phypa_156018) expression is also induced in $P$. irregulare and $P$. debaryanum infected moss plants [18]. Thus, $P$. patens could induce auxin production and activates auxin signaling to induce defense gene expression. $C$. gloeosporioides produces auxin in the flowering plant Aeschynomene virginica [54]. The possible synthesis of auxin by C. gloeosporioides in P. patens tissues and its effect on moss defense needs further investigation. IAA can inhibit $P$. debaryanum growth in vitro, suggesting that the high auxin levels present in the GH3 double knockout plants increase resistance against this pathogen [22]. Auxin signaling is required for resistance against necrotrophs, and Arabidopsis mutant defective in the auxin pathway are more susceptible than wild-type plants to necrotrophic fungus such as Plectosphaerella cucumerina, Botrytis cinerea and Alternaria brassicicola [59-61]. Further studies are needed to understand the involvement of auxin homeostasis in moss resistance against $C$. gloeosporioides.

\section{Experimental Section}

\subsection{Isolation and Identification of Colletotrichum Strain}

One isolate of Colletotrichum spp. was obtained from lesions formed by natural infections in orange fruit peel tissue from Citrus reticulata Blanco "Ellendale". The lesions were dry, dark brown and sunken on the rind tissues. Fruits with disease symptoms were obtained from commercial packinghouse in Salto, Uruguay, at the harvest of September, 2013. Isolation was performed by cutting small sections from the border of the anthracnose-like lesions, which were surface sterilized with $1 \%$ sodium hypochlorite solution for $3 \mathrm{~min}$, rinsed in sterilized water and dried on a sterile paper in a laminar flow. The tissue segments were placed on Potato Dextrose Agar (PDA) medium in sterilized Petri plates and incubated at $28{ }^{\circ} \mathrm{C}$ for seven days. A monosporic culture was made and preserved in $25 \%$ glicerol at $-80{ }^{\circ} \mathrm{C}$. The Colletotrichum spp. isolate was grown on PDA at $28{ }^{\circ} \mathrm{C}$ for 10 days to generate spores. Mature and asymptomatic Valencia fruit were surface sterilized with 1\% sodium hypochlorite solution for $3 \mathrm{~min}$ then rinsing in sterilized distilled water and dried. A spore suspension was adjusted to $1 \times 10^{5} \mathrm{spores} / \mathrm{mL}$ 
and immediately $1 \mathrm{~mL}$ of the suspension was inoculated with a needle of a syringe between the flavedo and the albedo of three orange fruit (C. sinensis (L.) Osbeck cv. Valencia Late). After inoculation, each fruit was placed in a nylon bag separately, incubated for seven days at $28{ }^{\circ} \mathrm{C}$, with $90 \%-95 \%$ relative humidity and a light/dark cycle of 12/12 h. For DNA extraction, the monosporic isolate was grown on Potato Dextrose Broth at $28{ }^{\circ} \mathrm{C}$ during five days, the fungal biomass was filtered, dried at $28^{\circ} \mathrm{C}$ for two days and grinded with liquid nitrogen. Fifty milligram were used for extraction with the DNAeasy kit from Qiagen (Hilden, Germany). PCR was performed according to Lima et al. [62], using the universal primer ITS4 (5'-TCCTCCGCTTATTGATATGC-3') coupled with the species-specific primer CgInt for C. gloeosporioides (5'-GGCCTCCCGCCTCCGGGCGG-3'). The reaction contained $20 \mathrm{ng}$ of DNA in $50 \mu \mathrm{L}$ of $10 \times$ PCR buffer, $2.5 \mathrm{mM} \mathrm{MgCl}_{2}, 0.2 \mathrm{mM} \mathrm{dNTP}, 0.5 \mu \mathrm{M}$ of each oligonucleotides and $0.04 \mathrm{U}$ Taq DNA polymerase (Thermo Scientific, Vilnius, Lithuania). The PCR conditions were as follows: 40 cycles at $94{ }^{\circ} \mathrm{C}$ for $1 \mathrm{~min}, 54{ }^{\circ} \mathrm{C}$ for $1 \mathrm{~min}$ and $72{ }^{\circ} \mathrm{C}$ for $1 \mathrm{~min}$. A PCR fragment with the corresponding size was amplified and sequence analysis confirmed that the Colletotrichum isolate corresponds to C. gloeosporioides (isolate ICECgS1, Accession number: KT272173).

\subsection{Physcomitrella patens and Colletotrichum gloeosporioides Growth Conditions}

Physcomitrella patens Gransden wild-type isolate was grown on agar BCDAT medium. Moss colonies were generated as described previously [18], and grown at $22{ }^{\circ} \mathrm{C}$ under a photoperiod of $16 \mathrm{~h}$ light. Three-week-old colonies were used for all the experiments. C. gloeosporioides was cultivated on $24 \mathrm{~g} / \mathrm{L}$ PDA (Difco, Houston, TX, USA) at $28^{\circ} \mathrm{C}$.

\subsection{Colletotrichum gloeosporioides Inoculation and Staining}

Conidia were recovered from the orange mucilage of colonies grown on PDA. C. gloeosporioides inoculation was performed by spraying a $2 \times 10^{5}$ conidia/mL suspension in water. Symptom development of $C$. gloeosporioides-inoculated $P$. patens colonies was analyzed in three independent experiments using two Petri dishes containing 16 colonies each. C. gloeosporioides tissues were stained with $0.1 \%$ solophenyl flavine $7 \mathrm{GFE} 500$ in water for $10 \mathrm{~min}$, rinsed in water and visualized with epifluorescence [18]. Photographs were taken at the indicated times after inoculation and representative photographs are shown.

\subsection{Plant Cell Wall-Associated Defense Responses}

Cell wall modifications were detected with safranin-O staining according to Oliver et al. [18]. Tissues were incubated with $0.01 \%$ safranin-O in $50 \%$ ethanol for $5 \mathrm{~min}$. Bright field microscopy and fluorescence microscopy were performed with an Olympus BX61 microscope (Shinjuku-ku, Tokyo, Japan), and all images shown in this study were captured with the Cell F or MICROSUITE software package (Olympus, Tokyo, Japan).

\subsection{RNA Gel Blot Analysis}

Total RNA was isolated from water-treated and C. gloeosporioides-inoculated moss tissues using standard procedures based on phenol-chloroform extraction followed by $\mathrm{LiCl}$ precipitation. Each 
sample consisted of 48 colonies. Ten micrograms of total RNA were separated, transferred to nylon membranes, hybridized and washed as described previously [17]. A partial cDNA clone with high level of similarity to DIR-encoding genes from flowering plants [19], a $P A L$ and a $C H S$ cDNA [63], were amplified by PCR using universal primers or digested with restriction enzymes. Purified fragments were labelled with $\left[\alpha^{32} \mathrm{P}\right]-\mathrm{dCTP}$ using the Rediprime II Random Prime labelling system (GE Healthcare, Buckinghamshire, UK). The amount of RNA loaded was verified by the addition of ethidium bromide to the samples and photography under UV light after electrophoresis. Integrity and equal transfer of RNAs to the nylon membranes were confirmed by briefly visualizing the membranes under UV. The blots shown are representative examples of the results obtained in two independent experiments.

\subsection{GUS Staining}

In situ localization of GUS activity was performed according to Peleman et al. [64]. Tissues were stained at $37^{\circ} \mathrm{C}$ for $24 \mathrm{~h}$ before destaining in an increasing serial dilution of ethanol, mounted in water, visualized in an Olympus BX61 microscope (Shinjuku-ku, Tokyo, Japan), and images were captured with the Cell F software package (Olympus).

\subsection{NAA Treatment}

P. patens colonies were grown for 3 weeks on BCDAT medium and then transferred to medium supplemented with naphthaleneacetic acid (NAA) at a final concentrations of $10 \mu \mathrm{M}$.

\section{Conclusions}

In this study, we show that $P$. patens is an interesting plant to gain insight into cellular and molecular mechanisms involved in plant defense responses against pathogens like $C$. gloeosporioides that causes disease in important crops. Further studies can be performed in $P$. patens to identify plant genes involved in the defense response against $C$. gloeosporioides by targeted gene disruption [65]. During recent years, studies focused on moss metabolism have revealed significant differences between $P$. patens and flowering plants, including the absence of the hormone jasmonic acid in P. patens [20]. The phenylpropanoid and the auxin pathways represent defense mechanisms against pathogens already present in primitive land plants like mosses. Further studies are needed to understand the phenylpropanoid pathway in $P$. patens, including the identification of the different enzymes and the compounds produced.

\section{Acknowledgments}

We thank Eva Decker for the GH3::GUS reporter line. This work was supported by Agencia Nacional de Investigación e Innovación (ANII) [grant FCE2011_6095, fellowships POS_NAC_2012_1_8729 (G. Reboledo)], and Programa de Desarrollo de las Ciencias Básicas (PEDECIBA) Uruguay. The $P$. patens ESTs were obtained from the RIKEN Biological Research Center, Tsukuba, Japan. 


\section{Author Contributions}

Guillermo Reboledo performed the $C$. gloeosporioides inoculations, analyzed symptom development, fungal colonization, cell wall associated defenses and gene expression analysis. Raquel del Campo isolated the $C$. gloeosporioides strain form citrus, performed the reinoculation of citrus fruits and evaluated the symptoms. Alfonso Alvarez and Marcos Montesano participated in the gene expression analysis. Héctor Mara participated in the analysis of anthracnose symptoms caused by C. gloeosporioides in citrus fruits. Inés Ponce de León designed and supervised the study, performed the GUS accumulation studies, participated in the analysis of the symptoms, fungal colonization, cell wall associated defenses, and wrote the manuscript. All authors read and approved the final manuscript.

\section{Conflicts of Interest}

The authors declare no conflict of interest.

\section{References}

1. Ponce de León, I.; Montesano, M. Activation of defense mechanisms against pathogens in mosses and flowering plants. Int. J. Mol. Sci. 2013, 14, 3178-3200.

2. Morel, J.B.; Dangl, J.L. The hypersensitive response and the induction of cell death in plants. Cell Death Differ. 1997, 4, 671-683.

3. Dickman, M.B.; Park, Y.K.; Oltersdorf, T.; Li, W.; Clemente, T.; French, R. Abrogation of disease development in plants expressing animal antiapoptotic genes. Proc. Natl. Acad. Sci. USA 2001, 98, 6957-6962.

4. Govrin, E.M.; Levine, A. The hypersensitive response facilitates plant infection by the necrotrophic pathogen Botrytis cinerea. Curr. Biol. 2000, 10, 751-757.

5. Glazebrook, J. Contrasting mechanisms of defense against biotrophic and necrotrophic pathogens. Annu. Rev. Phytopathol. 2005, 43, 205-227.

6. Robert-Seilaniantz, A.; Grant, M.; Jones, J.D. Hormone crosstalk in plant disease and defense: More than just jasmonate-salicylate antagonism. Annu. Rev. Phytopathol. 2011, 8, 317-343.

7. Robert-Seilaniantz, A.; Navarro, L.; Bari, R.; Jones, J.D. Pathological hormone imbalances. Curr. Opin. Plant Biol. 2007, 10, 372-379.

8. Agrios, G.N. Plant Pathology, 5th ed.; Elsevier Academic Press: San Diego, CA, USA, 2005; pp. 487-500.

9. O’Connell, R.J.; Thon, M.R.; Hacquard, S.; Amyotte, S.G.; Kleemann, J.; Torres, M.F.; Damm, U.; Buiate, E.A.; Epstein, L.; Alkan, N.; et al. Lifestyle transitions in plant pathogenic Colletotrichum fungi deciphered by genome and transcriptome analyses. Nat. Genet. 2012, 44, 1060-1065.

10. Gan, P.; Ikeda, K.; Irieda, H.; Narusaka, M.; O’Connell, R.J.; Narusaka, Y.; Takano, Y.; Kubo, Y.; Shirasu, K. Comparative genomic and transcriptomic analyses reveal the hemibiotrophic stage shift of Colletotrichum fungi. New Phytol. 2013, 197, 1236-1249.

11. Hyde, K.D.; Cai, L.; Cannon, P.F.; Crouch, J.A.; Crous, P.W.; Damm, U.; Goodwin, P.H.; Chen, H.; Johnston, P.R.; Jones, E.B.G.; et al. Colletotrichum-names in current use. Fungal Divers. 2009, 39, 147-182. 
12. Timmer, L.W.; Brown, G.E.; Sitko, S.E. The role of Colletotrichum spp. in postharvest anthracnose of citrus and survival of C. acutatum on fruit. Plant Dis. 1998, 82, 415-418.

13. Brown, G.E. Factors affecting postharvest development of Colletotrichum gloeosporioides in citrus fruits. Phytopathology 1975, 65, 404-409.

14. Taverner, P. Anthracnose. Packer Newslett. 2003, 71, 1-5.

15. Brown, G.E.; Barmore, C.R. The effect of ethylene on susceptibility of Robinson tangerines to anthracnose. Phytopathology 1977, 67, 120-123.

16. Akita, M.; Lehtonen, M.T.; Koponen, H.; Marttinen, E.M.; Valkonen, J.P. Infection of the Sunagoke moss panels with fungal pathogens hampers sustainable greening in urban environments. Sci. Total Environ. 2011, 409, 3166-3173.

17. Ponce de León, I.; Oliver, J.P.; Castro, A.; Gaggero, C.; Bentancor, M.; Vidal, S. Erwinia carotovora elicitors and Botrytis cinerea activate defense responses in Physcomitrella patens. BMC Plant Biol. 2007, 7, 52.

18. Oliver, J.P.; Castro, A.; Gaggero, C.; Cascón, T.; Schmelz, E.A.; Castresana, C.; Ponce de León, I. Pythium infection activates conserved plant defense responses in mosses. Planta 2009, 230, 569-579.

19. Ponce de León, I.; Schmelz, E.A.; Gaggero, C.; Castro, A.; Alvarez, A.; Montesano, M. Physcomitrella patens activates reinforcement of the cell wall, programmed cell death and accumulation of evolutionary conserved defence signals, such as salicylic acid and 12-oxophytodienoic acid, but not jasmonic acid, upon Botrytis cinerea infection. Mol. Plant Pathol. 2012, 13, 960-974.

20. Lehtonen, M.T.; Akita, M.; Frank, W.; Reski, R.; Valkonen, J.P. Involvement of a class III peroxidase and the mitochondrial protein TSPO in oxidative burst upon treatment of moss plants with a fungal elicitor. Mol. Plant Microbe Interact. 2012, 25, 363-371.

21. Machado, L.; Castro, A.; Hamberg, M.; Bannenberg, G.; Gaggero, C.; Castresana, C.; Ponce de León I. The Physcomitrella patens unique alpha-dioxygenase participates in both developmental processes and defense responses. BMC Plant Biol. 2015, 15, 45.

22. Mittag, J.; Šola, I.; Rusak, G.; Ludwig-Müller, J. Physcomitrella patens auxin conjugate synthetase (GH3) double knockout mutants are more resistant to Pythium infection than wild type. J. Plant Physiol. 2015, 183, 75-83.

23. Agostini, J.P.; Timmer, L.W.; Mitchell, D.J. Morphological and pathological characteristics of strains of Colletotrichum gloeosporioides from citrus. Phytopathology 1992, 82, 1377-1382.

24. Flaishman, M.A.; Hwang, C.H.; Kolattukudy, P.E. Involvement of protein phosphorylation in the induction of appressorium formation in Colletotrichum gloeosporioides by its host surface wax and ethylene. Physiol. Mol. Plant Pathol. 1995, 47, 103-117.

25. Kim, Y.K.; Kawano, T.; Li, D.; Kolattukudy, P.E. A mitogen-activated protein kinase kinase required for induction of cytokinesis and appressorium formation by host signals in the conidia of Colletotrichum gloeosporioides. Plant Cell 2000, 12, 1331-1343.

26. Cai, Z.; Li, G.; Lin, C.; Shi, T.; Zhai, L.; Chen, Y.; Huang, G. Identifying pathogenicity genes in the rubber tree anthracnose fungus Colletotrichum gloeosporioides through random insertional mutagenesis. Microbiol. Res. 2013, 168, 340-350.

27. Mendgen, K.; Struck, C.; Voegele, R.T.; Hahn, M. Biotrophy and rust haustoria. Physiol. Mol. Plant Pathol. 2000, 56, 141-145. 
28. Perfect, S.E.; Hughes, H.B.; O’Connell, R.J.; Green, J.R. Colletotrichum: A model genus for studies on pathology and fungal-plant interactions. Fungal Genet. Biol. 1999, 27, 186-198.

29. Barreto, A.L.H.; Vasconcelos, I.M.; Grangeiro, T.B.; Melo, V.M.M.; Matos, T.E.; Eloy, Y.R.G.; Fernandes, C.F.; Torres, D.C.; Freire-Filho, F.R.; Freire, F.C.O.; et al. Infection process and host defense responses in compatible and incompatible interactions between cowpea (Vigna unguiculata) and Colletotrichum gloeosporioides. Int. J. Plant Sci. 2007, 168, 193-203.

30. Rockenbach, M.F.; Boneti, J.I.; Cangahuala-Inocente, G.C.; Gavioli-Nascimento, M.C.A.; Guerra, M.P . Histological and proteomics analysis of apple defense responses to the development of Colletotrichum gloeosporioides on leaves. Physiol. Mol. Plant Pathol. 2015, 89, 97-107.

31. Wharton, P.S.; Uribeondo, J.D. The biology of Colletotrichum acutatum. Anales Jard Bot. Madrid 2004, 61, 3-22.

32. O’Connell, R.; Perfect, S.; Hughes, B.; Carzaniga, R.; Bailey, J.; Green, J. Dissecting the cell biology of Colletotrichum infection processes. In Colletotrichum: Host Specificity, Pathology and Host-Pathogen Interaction; Prusky, D., Freeman, S., Dickman, M.B., Eds.; APS Press: St. Paul, MN, USA, 2000; pp. 57-77.

33. Latunde-Dada, A.O. Colletotrichum: Tales of forcible entry, stealth, transient confinement and breakout. Mol. Plant Pathol. 2001, 2, 187-198.

34. Ogle, H.J.; Gowanlock, D.H.; Irwin, J.A.G. Infection of Stylosanthes guianensis and S. scabra by Colletotrichum gloeosporioides. Phytopathology 1990, 80, 837-842.

35. Reski, R. Physcomitrella and Arabidopsis: The David and Goliath of reverse genetics. Trends Plant Sci. 1998, 3, 209-210.

36. Kim, K.H.; Yoon, J.B.; Park, H.G.; Park, E.W.; Kim, Y.H. Structural modifications and programmed cell death of chili pepper fruit related to resistance responses to Colletotrichum gloeosporioides infection. Phytopathology 2004, 94, 1295-1304.

37. Yakoby, N.; Kobiler, I.; Dinoor, A.; Prusky, D. pH regulation of pectate lyase secreation modulates the attack of Colletotrichum gloeosporioides on avocado fruits. Appl. Environ. Microbiol. 2000, 66, $1026 \mathrm{e} 30$.

38. Alkan, N.; Friedlander, G.; Ment, D.; Prusky, D.; Fluhr, R. Simultaneous transcriptome analysis of Colletotrichum gloeosporioides and tomato fruit pathosystem reveals novel fungal pathogenicity and fruit defense strategies. New Phytol. 2015, 205, 801-815.

39. Hiruma, K.; Fukunaga, S.; Bednarek, P.; Pislewska-Bednarek, M.; Watanabe, S.; Narusaka, Y.; Shirasu, K.; Takano, Y. Glutathione and tryptophan metabolism are required for Arabidopsis immunity during the hypersensitive response to hemibiotrophs. Proc. Natl. Acad. Sci. USA 2013, 110,9589-9594.

40. Lehtonen, M.T.; Marttinen, E.M.; Akita, M.; Valkonen, J.P.T. Fungi infecting cultivated moss can also cause diseases in crop plants. Ann. Appl. Biol. 2012, 160, 298-307.

41. Torres, M.A.; Jones, J.D.; Dangl, J.L. Reactive oxygen species signaling in response to pathogens. Plant Physiol. 2006, 141, 373-378.

42. Nomura, H.; Komori, T.; Uemura, S.; Kanda, Y.; Shimotani, K.; Nakai, K.; Furuichi, T.; Takebayashi, K.; Sugimoto, T.; Sano, S.; et al. Chloroplast-mediated activation of plant immune signalling in Arabidopsis. Nat. Commun. 2012, 3, 926. 
43. Trotta, A.; Rahikainen, M.; Konert, G.; Finazzi, G.; Kangasjärvi, S. Signalling crosstalk in light stress and immune reactions in plants. Philos. Trans. R. Soc. Lond. B 2014, 369, 20130235.

44. Kwon, K.C.; Verma, D.; Jin, S.; Singh, N.D.; Daniell, H. Release of proteins from intact chloroplasts induced by reactive oxygen species during biotic and abiotic stress. PLOS ONE 2013, 8, e67106.

45. Caplan, J.L.; Mamillapalli, P.; Burch-Smith, T.M.; Czymmek, K.; Dinesh-Kumar, S.P. Chloroplastic protein NRIP1 mediates innate immune receptor recognition of a viral effector. Cell 2008, 132, 449-462.

46. Caplan, J.L.; Kumar, A.S.; Park, E.; Padmanabhan, M.S.; Hoban, K.; Modla, S.; Czymmek, K.; Dinesh-Kumar, S.P. Chloroplast dtromules function during innate immunity. Dev. Cell 2015, 34, $45-57$.

47. Freytag, S.; Arabatzis, N.; Hahlbrock, K.; Schmelzer, E. Reversible cytoplasmic rearrangements precede wall apposition, hypersensitive cell death and defense-related gene activation in potato/Phytophthora infestans interactions. Planta 1994, 194, 123-135.

48. Wolf, L.; Rizzini, L.; Stracke, R.; Ulm, R.; Rensing, S.A. The molecular and physiological responses of Physcomitrella patens to ultraviolet-B radiation. Plant Physiol. 2010, 153, 1123-1134.

49. Koduri, P.K.; Gordon, G.S.; Barker, E.I.; Colpitts, C.C.; Ashton, N.W.; Suh, D.Y. Genome-wide analysis of the chalcone synthase superfamily genes of Physcomitrella patens. Plant Mol. Biol. 2010, 72, 247-263.

50. Tavernier, V.; Cadiou, S.; Pageau, K.; Laugé, R.; Reisdorf-Cren, M.; Langin, T.; Masclaux-Daubresse, C. The plant nitrogen mobilization promoted by Colletotrichum lindemuthianum in Phaseolus leaves depends on fungus pathogenicity. J. Exp. Bot. 2007, 58, 3351-3360.

51. Samac, D.A.; Peñuela, S.; Schnurr, J.A.; Hunt, E.N.; Foster-Hartnett, D.; Vandenbosch, K.A.; Gantt, J.S. Expression of coordinately regulated defence response genes and analysis of their role in disease resistance in Medicago truncatula. Mol. Plant Pathol. 2011, 12, 786-798.

52. Davin, L.B.; Lewis, N.G. Dirigent proteins and dirigent sites explain the mystery of specificity of radical precursor coupling in lignan and lignin biosynthesis. Plant Physiol. 2000, 123, 453-462.

53. Robinson, M.; Riov, J.; Sharon, A. Indole-3-acetic acid biosynthesis in Colletotrichum gloeosporioides f. sp. aeschynomene. Appl. Environ. Microbiol. 1998, 64, 5030-5032.

54. Maor, R.; Haskin, S.; Levi-Kedmi, H.; Sharon, A. In planta production of indole-3-acetic acid by Colletotrichum gloeosporioides f. sp. aeschynomene. Appl. Environ. Microbiol. 2004, 70, 1852-1854.

55. Reineke, G.; Heinze, B.; Schirawski, J.; Buttner, H.; Kahmann, R.; Basse, C.W. Indole-3-acetic acid (IAA) biosynthesis in the smut fungus Ustilago maydis and its relevance for increased IAA levels in infected tissue and host tumor formation. Mol. Plant Pathol. 2008, 9, 339-355.

56. Bierfreund, N.M.; Reski, R.; Decker, E.L. Use of an inducible reporter gene system for the analysis of auxin distribution in the moss Physcomitrella patens. Plant Cell Rep. 2003, 21, 1143-1152.

57. Ludwig-Müller, J.; Jülke, S.; Bierfreund, N.M.; Decker, E.L.; Reski, R. Moss (Physcomitrella patens) GH3 proteins act in auxin homeostasis. New Phytol. 2009, 181, 323-338.

58. Menand, B.; Calder, G.; Dolan, L. Both chloronemal and caulonemal cells expand by tip growth in the moss Physcomitrella patens. J. Exp. Bot. 2007, 58, 1843-1849. 
59. Lahey, K.A.; Yuan, R.; Burns, J.K.; Ueng, P.P.; Timmer, L.W.; Chung, K.R. Induction of phytohormones and differential gene expression in citrus flowers infected by the fungus Colletotrichum acutatum. Mol. Plant Microb. Interact. 2004, 17, 1394-1401.

60. Llorente, F.; Muskett, P.; Sánchez-Vallet, A.; López, G.; Ramos, B.; Sánchez-Rodríguez, C.; Jordá, L.; Parker, J.; Molina, A. Repression of the auxin response pathway increases Arabidopsis susceptibility to necrotrophic fungi. Mol. Plant. 2008, 1, 496-509.

61. Qi, L.; Yan, J.; Li, Y.; Jiang, H.; Sun, J.; Chen, Q.; Li, H.; Chu, J.; Yan, C.; Sun, X.; et al. Arabidopsis thaliana plants differentially modulate auxin biosynthesis and transport during defense responses to the necrotrophic pathogen Alternaria brassicicola. New Phytol. 2012, 195, 872-882.

62. Lima, W.G.; Spósito, M.B.; Amorim, L.; Goncalves, F.P.; de Filho, P.A.M. Colletotrichum gloeosporioides, a new causal agent of citrus post-bloom fruit drop. Eur. J. Plant Pathol. 2011, 131, 157-165.

63. Nishiyama, T.; Fujita, T.; Shin-I, T.; Seki, M.; Nishide, H.; Uchiyama, I.; Kamiya, A.; Carninci, P.; Hayashizaki, Y.; Shinozaki, K.; et al. Comparative genomics of Physcomitrella patens gametophytic transcriptome and Arabidopsis thaliana: Implication for land plant evolution. Proc. Natl. Acad. Sci. USA 2003, 100, 8007-8012.

64. Peleman, J.; Boerjan, W.; Engler, G.; Seurinck, J.; Botterman, J.; Alliote, T.; van Montagu, M.; Inzé, D. Strong cellular preference in the expression of a housekeeping gene of Arabidopsis thaliana encoding $S$-adenosylmethionine synthetase. Plant Cell 1989, 1, 81-93.

65. Schaefer, D.G. A new moss genetics: Targeted mutagenesis in Physcomitrella patens. Annu. Rev. Plant Biol. 2002, 53, 477-501.

(C) 2015 by the authors; licensee MDPI, Basel, Switzerland. This article is an open access article distributed under the terms and conditions of the Creative Commons Attribution license (http://creativecommons.org/licenses/by/4.0/). 